\title{
A Contrastive Study of Cohesion in English and Chinese
}

\author{
Jian-Sheng Yang ${ }^{1}$ \\ ${ }^{1}$ English Department, College of Humanities and Foreign Languages, Xi'an University of Science and \\ Technology, Xi'an, China \\ Correspondence: Jian-Sheng Yang, College of Humanities and Foreign Languages, Xi'an University of Science \\ and Technology, No. 2,Yanta Road (Southern Section), Xi'an 710054, China. E-mail:18091384316@163.com
}

\author{
Received: September 19, 2014 Accepted: October 14, 2014 Online Published: November 25, 2014 \\ doi:10.5539/ijel.v4n6p118 URL: http://dx.doi.org/10.5539/ijel.v4n6p118
}

\begin{abstract}
Cohesion, as the primary means of reaching discourse coherence, is one of the most important aspects of textual linguistics. Both English and Chinese employ cohesive devices, but they belong to different language families and the ways of their thought are different from each other, so there exists much dissimilarity between Chinese cohesion and English cohesion. A contrastive study on the cohesion in Chinese and English is of much significance for the research of the contrastive linguistics. This thesis mainly explores and studies the differences of Chinese discourse cohesion and English discourse cohesion. It is hoped that a better understanding can be obtained through this study.
\end{abstract}

Keywords: discourse cohesion, Chinese cohesion, English cohesion

\section{Introduction}

Nowadays, cross-culture communications are playing a more and more important role in today's world. Chinese and English belong to different language families; what's more, there are many differences of ways of thinking between them, so a contrastive study between Chinese and English is very necessary.

Moreover, with the new development in linguistic research, more and more attention has been paid to the textual study, because the subject that it studies is beyond the sentence level, such as a conversation or a text even an article, which is much larger and more complicated than a sentence. Cohesion, as one of the most important aspects in discourse, has been studied by many linguists. Halliday and Hasan (2001) have given us a very systematic and complete introduction of cohesion in Cohesion in English. Hu (1995), as one of the most famous linguists in China, also developed his new theory of cohesion in Discourse Cohesion and Coherence. Both of them have laid the importance of cohesion in the study of discourse. On the base of these researchers' studies, this thesis is trying to make a contrastive study of the different characteristics of cohesion in Chinese and English.

\section{Definition and Classification of Discourse Cohesion}

\subsection{Definition of Discourse Cohesion}

Discourse cohesion serves as an adhesive in a discourse which is an important device to reach discourse coherence. "Discourse cohesion is network of lexical, grammatical, and other relations which provide links between various parts of a text. These relations or ties organize and, to some extent, create a text, for instance by requiring the reader to interpret words and expressions in the surrounding sentences and paragraphs" (Baker, 1991).

Halliday and Hasan (2001) define cohesion as the various meaning relations existing in the discourse so as to make the whole text a discourse. They point out that there exists cohesion when the interpretation of one component depends on the interpretation of another component in the discourse. Thompson (2000) believes that cohesion is the language devices of the coherence. Li (2001) argues that cohesion refers to the employment of grammatical and lexical devices so as to achieve the discourse coherence. From the above, it is very clear that cohesion is a matter of lexical or grammatical devices in a discourse which is essential to link several parts of a discourse in to a whole text or discourse.

\subsection{Classifications of Cohesive Devices}

Halliday and Hasan (2001) put the cohesive devices in English into two categories; one is grammatical cohesion, 
while the other is lexical cohesion. In the grammatical cohesion, there are several devices, such as reference, substitution, ellipsis and conjunction. In terms of lexical cohesion, there are devices such as repetition, general word, synonym, antonym, hyponym, and collocation.

\section{A Contrastive Study of Cohesion in English and Chinese}

Chinese and English belong to different language families, and there are many differences of ways of thinking between Chinese and English, so the ways of expressions are very different from each other. The most important contrast between Chinese and English is hypotaxis and parataxis. Chinese needs little connectives and conjunctions to form a coherent discourse, and cohesion in Chinese is much simpler than that in English. English's hypotactic prominence makes great differences Chinese cohesions, which means in English the grammatical meanings and logical relationships in the discourse are expressed by the employment of many language forms, such as conjunctions and connectives. Then, Chinese tends to use covert means to create cohesion, but English tends to adopt overt cohesive devices to create coherence in a discourse.

The above analysis is just a very general contrastive study of the differences in English cohesion and Chinese cohesion. The following passages explore and describe the different characteristics of each cohesive device in English and Chinese.

\subsection{A Contrastive Study of Grammatical Cohesion in English and Chinese}

Grammatical cohesion is more commonly used in the English discourse to achieve coherence than in the Chinese discourse. It refers to the employment of grammatical means so as to establish semantic relations within a discourse. In the following passages, a contrastive study of grammatical cohesion in Chinese and English is given illustrated by some examples.

\subsubsection{Reference}

Reference is the most obvious one in all cohesive devices. Hu (1995) thinks that reference refers to using one component as the referential point of another component in the discourse. As long as we totally understand and master reference, we can make clear the semantic relation between one component and the corresponding component in the discourse. There is a large difference in personal reference and demonstrative reference between Chinese discourse and English discourse.

Personal reference refers to using the pronouns to substitute the nouns which appear in the context. It can be divided into two types: one is the anaphora, that is, to use one component referring to the component which has occurred in the previous context; another is the cataphora that is to use one component to refer to the component which will appear below. While the Chinese sometimes employs zero-anaphora, and the meaning of the previous and below is naturally connected, without any connective words. For example:中国将努力促进国内粮食增产, 在正常情况下,粮食自给率不低于 $95 \%$, 净出口量不超过国内消费量的 $5 \%$ 。 In this example, “国内” refers back to “中国”, so the cohesion between the two appears. While in the “食物自给率” there exists a zero-anaphora. The relationship between them is not pointed out, but we can know the meaning through the context naturally.

The difference of cataphora is more obvious between Chinese and English than anaphora. It is very common in the English complex sentences that pronoun appears before the referred component, but it is very rare in Chinese. Here is an example: English version: When he was a child, Peter always liked staying with that old man.

Chinese version: 当彼得还是个孩子时, 他很喜欢和那个老人呆在一起。

$\mathrm{Hu}$ (1995) remarks that demonstrative reference is that the speaker determines the meaning of the object through the distance of the object in the space and time. Chinese uses the demonstrative pronouns such as “这” and “那” to indicate the time, place ,quantity, properties of the object. While in English, it is often delivered "the", "this", "these", "those", "here" or "there" and other words to achieve cohesion. But the frequency of demonstrative pronoun employed in English and Chinese is very different. The definite articles exist in English but not in Chinese. For example:

Chinese version: A: 苹果在哪?

\section{B: 在那边。}

English version: A: Where are the apples?

\section{B: Over there.}

Although, in Chinese it is not pointed out which apple is wanted, but the “苹果” is the theme and the topic, it exists in the consciousness of A and B, but in English, "the" must be used to show which apple is wanted. 


\subsubsection{Substitution}

Substitution is also an important part of grammatical cohesion. Huang Guowen(2001) gives the definition that substitution refers to using the words such as "one", "do", "so" to replace the components which have appeared in the context. There are nominal substitution, verbal substitution and clausal substitution. For example:

English version: (1) I don't like white T-shirt, I like colored ones.

Chinese version: 我不喜欢白色的 $\mathrm{T}$ 恤, 我喜欢花的。

English version: (2) - He likes classic music very much, doesn't he?

-Yes, he does.

Chinese version: 一他很喜欢古典音乐, 对吧?

一对, 他喜欢典音乐。

English version: (3) —Do you think that he is a good student?

-Yes, I think so.

Chinese version: 一你觉得他是个好学生吗?

$$
\text { 一我想他是的。 }
$$

In the first example, "ones" replaces the term "T-shirt" in English; while in Chinese, we use a Chinese character “的” to replace "T-shirts". In the second example, we replace the predicate verb "like classic music" with "does"; in the third example, the "so" has replaced the clause "he is a good student", but the clause is omitted in Chinese version.

\subsubsection{Ellipsis}

Huang (2001) remarks that ellipsis mainly refers to the omission the components which have already been mentioned in the context, or which have been known to the two sides of the communication, but do not appear in specific parts of the context. As it is previously analyzed, ellipsis is the more commonly used in Chinese than in English. For example:

English version: She wore the blue dress, but the pink suits her better.

Chinese version: 她穿了一件蓝色的裙子, 但是那条粉色的更适合她。

In the original text, the "dress" has been mentioned above, so in the second sentence "dress" after "the pink" is omitted. In the Chinese version, we also omit the “裙子”.

\subsubsection{Conjunction}

Halliday and Hasan (2001) point out that using conjunction is an important cohesive device. The employment of conjunctions can establish a semantic relationship between contexts. Conjunction refers to the cohesive device used to establish logic relations among clauses. The logic relation can be clear to readers with the employment of various kinds of conjunctions. Connective words may be conjunctions, adverbs, prepositions or prepositional phrases, even clauses with connective meaning.

Chinese discourses use fewer conjunctions than English, and their semantic relation is usually realized by covert means, so it needs little connectives and the semantic relation is formed naturally through the meaning of words or phrases. However, English is hypotactic prominent, which focuses on the forms of language and need many connective words to make the discourse logic and complete in semantic meaning. Here are some examples:

There was I, straight as a young poplar, with my firelock, and my bayonet, and my spatter dashes, and my stock sawing my jaws off, and my accouterments shining like seven stars!

By the analysis of the above example, we can find in the source language, the additive word "and" is used to connect the clause, which can not only make the grammatical structure complete, but also show that the speaker is not willing to finish his speech after he finishes his first sentence, and wants to add something new.

忙到除夕夜才松口气。全家团圆, 坐下来吃“年夜饭”。

In this example, there is no conjunction in the source language, but the semantic meaning is coherent and complete.

\subsection{A Contrastive Study of Lexical Cohesion in English and Chinese}

Lexical cohesion is more commonly used in the Chinese discourse. It refers to the application of lexical means to make the discourse coherent. It can enhance the stylistic function as well as build discourse cohesion both in 
English and Chinese. It includes repletion, general words, synonyms, antonyms, and so on.

\subsubsection{Repetition}

$\mathrm{Hu}(1995)$ points out that the most direct way of lexical cohesion is the repetition of the words with same forms and same semantic meaning in the same discourse. In other words, it refers to a conscious repetition of a certain word to make a kind of cohesion among sentences in a discourse so as to highlight certain thoughts or emphasize certain emotion, which can make the theme of the discourse consistent. Comparatively speaking, Chinese tends to use more repetition than English. Here are some examples,

世有伯乐, 然后有千里马。千里马常有, 而伯乐不常有。

In this example, “伯乐” and “千里马” appear twice. Chinese achieve discourse cohesion through repetition; therefore, there is a sense of rhyme. It is very common that Chinese tends to employ repetitions in a discourse, while English tends to use synonyms to replace the repeated word. For example,

Chinese version: 低进度就等于停步, 甚至等于后退。要抓住机会, 现在就是最好的机会。

English Version 1: Low speed equals stagnation and even retreat; opportunity

must be grasped. The present offers excellent chance.

Version 2: Slow growth equals stagnation and even retrogression. We must grasp opportunity; the present offers an excellent one.

Chinese use repetition of the words to achieve cohesion, for example “机会” this word appears twice, but in the English version, we reproduce the discourse cohesion through using synonyms such as opportunity—chance, or substitution, to use "one" to substitute the word "opportunity".

\subsubsection{General Word}

We can use some words which can generally refer to the person, thing or place which has appeared in other places of the discourse. Hu (1995) points out that these words are called general words, such as person, thing, fact, and place in English, and “人”, “东西”, “物”, “事”, “地方” in Chinese. The employment of general words can enrich the vocabularies and make the discourse briefer, then achieve the discourse cohesion. Here is an example,

Chinese version: 动身访美之前, 一位旧时同窗写来封航空信, 再三托付我为他带几颗生麥核。东西倒不 占分量, 可是用途却很蹊跷。

English version: Before I set out for the US, a former schoolmate of mine wrote to me by airmail, asking me in all earnest to bring him some raw date stones. They were not heavy in weight, yet I was curious about their use.

In Chinese version, the word “东西” in the second sentence points back to the word “生麥核” in the first sentence, because the word “东西” has a wide usage. These two sentences are closely connected by this general word; while the English version achieves cohesion by employing the cohesive device of personal reference. So we use "they" to point back to "some raw date stones".

\subsubsection{Synonym and Antonym}

Synonymy includes two aspects; one is synonymy, and the other is near synonymy. It refers to the corresponding relation among different words with same meaning or similar meaning (Hu \& Zhu, 2001). It is an important lexical cohesive device in a discourse. Comparatively speaking, it is very common to have synonyms co-occur in the discourse in Chinese, but when we translate Chinese discourse into English, we just only need to use one word to express the semantic meaning. Here is an example,

Chinese version: 中国有五千年的悠久历史, 文化丰富, 是世界四大文明古国之一。所有中国人为此感到 无比的自豪与骄傲。

English version: China, as one of the four old civilizations in the world, has a long history and profound culture. All Chinese are very proud of it.

In the Chinese version, we use “自豪” and “骄傲”, but in the English version, we use one word "proud”. It is also true that no matter in Chinese or English, we should try to avoid unnecessary repetition, so we should choose a synonym to change the repeated word according to a concrete context.

Antonyms are the extreme of synonyms. It can establish a contrastive relation with distinguished meaning between two words, including oppositeness, complementarities, and relational oppositeness and so on. (Hu, 1995) Antonyms appearing in the same discourse can make two different components of the discourse form a contrast in terms of meaning. The follow example may show that the employment of antonyms can be functioned as a 
good cohesive device.

English version: It was the best of times, it was the worst of times, it was the age of wisdom, it was the age of foolishness, it was the epoch of belief, it was the epoch of incredulity, it was the season of light, it was the season of darkness, it was the spring of hope, it was the winter of despair, we had everything before us, we had nothing before us, we were all going direct to heaven, we were all going direct to the other way. (A Tale of Two Cities by C. Dickens)

Chinese version: 那是最好的年月, 那是最坏的年月, 那是智慧的时代, 那是愚蚌的时代 , 那是信仰的新 纪元, 那是怀疑的新纪元, 那是光明的季节, 那是黑暗的季节, 那是希望的春天, 那是绝望的冬天, 我 们将拥有一切, 我们将一无所有, 我们直接上天堂, 我们直接下地狱!

In the English text, best \& worst, wisdom \& foolishness, belief \&incredulity, light \& darkness, hope \& despair, and everything \& nothing are all antonyms of each other. They form a special kind of discourse cohesion and make the discourse have a perfect contrast in semantic meaning. In the Chinese text, several pairs of antonyms are also employed.

\subsubsection{Hyponym}

Hyponymy is meaning inclusiveness or mater of class membership. The upper term in this sense relation, i.e. the class name, is called superordinate, and the lower terms, the members, hyponyms. (Hu, 1995) It is very common to use hyponyms in a discourse, and it is an important cohesive device in the discourse.

English version: You will need to take some tools with you; you can get a hammer, a saw and a screwdriver from big department stores.

Chinese version：你得随身带着锤子、锯子和改雉，这些工具从百货商店就能买到。

In this example, hammer, saw, and screwdriver are all treated as the hyponyms of tools. In the Chinese version, “锤子”, “锯子” and “改雉” are also treated as the hyponyms of “工具”.

\subsubsection{Collocation}

$\mathrm{Hu}$ (2007) points out that collocation, which is also called the relation of the co-occurrence, refers to the co-occurrence tendency of words in a discourse. It is a very important lexical cohesive device. There is some semantic relation between the co-occurrence words, such as the follow pairs of words: ice, cold, snow, white; star, night, candle, flame and flicker. Collocation, like the antonyms, synonymy and hyponymy, can also appears in one clause, or in different clauses in a discourse. Because of different culture and habits of expressions, there exists some difference in Chinese and English. Some collocations may be common in Chinese, but rare or strange in English. Here is the example,

Chinese version: 虽然中国妇女在平等方面取得了巨大的进步，但还未完全实现平等就业机会。

English version: It is true that Chinese women have made enormous strides toward equality. But the goals of equal opportunity of employment for women have not been fully realized.

It is coherent and acceptable in Chinese to have this collocation “实现平等就业机会”, but there is no such expression in English. In English, we often say "realize / accomplish the goal/aim.

\section{Conclusion}

From the above analysis, it is very clear that there are great differences between Chinese and English, so the efforts should be made to detour the traps resulted from the unique characteristic of cohesion. Chinese shows paratactic prominence that means the grammatical meanings and logical relationships in the discourse are expressed by the meanings of the words and clauses in it, without the employment of any language forms, such as conjunctions and connectives. English is hypotactic prominent which means in English the grammatical meanings and logical relationships in the discourse are expressed by the employment of many language forms, such as conjunctions and connectives. Therefore, the cohesive devices are essentially different in Chinese and English.

The difference of the discourse cohesion between Chinese and English is just the tip of the iceberg in the oceanic contrast. The hope is submitted to make further study on the textual cohesion.

\section{References}

Baker, M. (1991). In Other Words: A Coursebook On Translation. Beijing: Foreign Language Teaching and Research Press.

Cheng, H. W., \& Li, Y. T. (2004). A New Chinese English Translation. Shanghai: Shanghai Foreign Language 
Education Press.

Halliday, M. A. K., \& Hasan, R. (2001). Cohesion in English. Beijing: Foreign Language Teaching and Research Press.

Hu, M. L. (2007). Text Coherence and Translation. Chengdu: Bashu Publishing House.

Hu, Z. G. (1995). Discourse Cohesion and Coherence. Shanghai: Shanghai Foreign Language Education Press.

Hu, Z. L., \& Zhu, Y. S. (2005). An Introduction to Functional Grammar. Beijing: Peking University Press.

Huang, G. W. (2001). Discourse Analysis: Theory and Practice of the Advertisement Discourse. Shanghai: Shanghai Foreign Language Education Press.

Kong, Z. L. (2003). English to Chinese Translation. Shanghai: Shanghai Foreign Language Education Press.

Li, Y. X. (2001). An Introduction to Discourse Translation. Beijing: Chinese Translation Publishing Company.

Thompson, G. (2000). Introducing Functional Grammar. Beijing: Foreign Language Teaching and Research Press.

Zhang, D. L., \& Liu, R. S. (2003). Discourse Coherence and Cohesion Theory Development and Application. Shanghai: Shanghai Foreign Language Education Press.

\section{Copyrights}

Copyright for this article is retained by the author(s), with first publication rights granted to the journal.

This is an open-access article distributed under the terms and conditions of the Creative Commons Attribution license (http://creativecommons.org/licenses/by/3.0/). 